\title{
Natural air leak test without submergence for spontaneous pneumothorax
}

\author{
Hidetaka Uramoto* and Fumihiro Tanaka
}

\begin{abstract}
Background: Postoperative air leaks are frequent complications after surgery for a spontaneous pneumothorax (SP). We herein describe a new method to test for air leaks by using a transparent film and thoracic tube in a closed system.

Method: Between 2005 and 2010, 35 patients underwent a novel method for evaluating air leaks without submergence, and their clinical records were retrospectively reviewed. The data on patient characteristics, surgical details, and perioperative outcomes were analyzed.

Results: The differences in the clinical background and intraoperative factors did not reach a statistically significant level between the new and classical methods. The incidence of recurrence was also equivalent to the standard method. However, the length of the operation and drainage periods were significantly shorter in patients evaluated using the new method than the conventional method. Further, no postoperative complications were observed in patients evaluated using the new method.
\end{abstract}

Conclusions: This simple technique is satisfactorily effective and does not result in any complications.

Keywords: spontaneous pneumothorax, air leak, operation, VATS

\section{Introduction}

SP remains a significant health problem because the recurrence rate is estimated to be approximately $10 \%$ $20 \%$, even after surgical management is performed [1]. Prolonged air leaks (PALs) are the main reason for prolonged thoracic tube drainage, a prolonged hospital stay, and increased costs [2]. We often experience postoperative air leaks in spite of there being no air leaks intraoperatively. Therefore, the procedure for evaluating air leaks itself might be a problem.

The submersion method, which is the most popular way of screening for air leaks [3], requires that the lung parenchyma be held to identify the leak point. Furthermore, most procedures are performed in a limited space by VATS. However, holding the lung puts it in a state that is far from its natural and physiological state. A practical technique that avoids this unnatural positioning has not been sufficiently discussed. We herein introduce a new technique that uses a transparent film and

\footnotetext{
* Correspondence: hidetaka@med.uoeh-u.ac.jp

Second Department of Surgery, School of Medicine, University of

Occupational and Environmental Health, Kitakyushu 807, Japan
}

drainage tube. This method is easy and efficient, and does not appear to cause any complications. The purpose of this study was to determine the clinical outcome using the new method for detecting air leak

\section{Patients and methods}

The institutional review board approved this study for the use of the data collection and analysis. From 2005 to 2010, two hundred twenty-one patients requiring surgery due to SP were included in this retrospective study conducted at the University of Occupational and Environmental Health. Preoperative investigations included chest radiography and a high-resolution computed tomographic (CT) scan of the thorax. Six patients with ipsilateral lung cancer and 1 lymphangioleiomyomatosis (LAM) were excluded from the analyses. Finally, a total of 214 patients were included in the present series. Thirty-five patients underwent this simple test for air leaks, and their clinical records were retrospectively reviewed. The indications for surgical treatment of patients with SP included PAL, tension pneumothorax, the obvious existence of bulla lesions at first

\section{() Biomed Central}


presentation, hemopneumothorax, the occupation of the patient, and ipsilateral or contralateral recurrences. Data were collected for all patients and included a detailed history, age, sex, and smoking habits, past history of episodes of pneumothorax, treatment modalities, and surgical details. Postoperative variables included the pleurodesis, postoperative complications, and the duration of chest drainage. The patients were discharged from the hospital after surgery. Follow-up data were collected via attendance at the outpatient department.

\section{Surgical technique and patient management}

All patients underwent general anesthesia and single lung ventilation with a double-lumen endotracheal tube. The patients were placed in the lateral decubitus position. A 5 or $10 \mathrm{~mm} 0^{\circ}$ video thoracoscope was inserted in the 7th intercostal space in the midaxillary line making use of the hole for the preoperative drainage tube. After inspection of the thoracic cavity, one or two additional ports were placed. The 5 or $10 \mathrm{~mm}$ working ports were placed in the 5 th intercostal space between the scapula tip and the anterior axillary line. The blebs were grasped with an endograsp and excised with an endoGIA stapling device (Auto Suture Company Division, United States Surgical Corporation, Norwalk, USA), ECHELON device (Ethicon Endo-Surgery, Inc; Cincinnati, Ohio) or were hand-stitched. One hundred ninety and 11 patients have undergone machine-mediated repair and hand stitching for blebs respectively. Both methods applied for 9 cases and 4 cases were performed only abrasion. The covering technique used was the (PGA) sheet (Neoveil) with fibrin-glue (Beriplast P; Marburg, Germany or Bolheal: The Chemo-Sero-Therapeutic Research Institute, Kumamoto, Japan). The new "natural" method that did not require submergence was as follows; the thoracic drainage tube was kept in the appropriate site through one of the port sites, and was not inserted into the interlobe after treatment of the bullous lesion. Next, the wounded area and port for drainage were temporarily closed by a transparent film (Tegaderm film 1626w $10 \times 12 \mathrm{~cm}$; 3 M Health Care, St. Paul. MN, USA), followed by connection between the drainage tube and thoracic bag (MERA Aquaseal D2; Senko Medical instrument Mfg, Co., ltd, Tokyo, Japan), and these were put in a low pressure suction machine (MS008-EX; Senko Medical instrument Mfg, Co., ltd). At the beginning of the surgical procedure, patients were ventilated at $15 \mathrm{~cm} \mathrm{H}_{2} \mathrm{O}$ at the maximum inspiratory pressure and examined for air leaks. If the covered film became convex, this suggested the presence of positive pressure in the thoracic space (Figure 1A). Finally, patients were tested for the presence of air leaks up to a pressure of $20 \mathrm{~cm} \mathrm{H}_{2} \mathrm{O}$ and negative suction of $5 \mathrm{~cm} \mathrm{H} \mathrm{H}_{2} \mathrm{O}$. If the transparent film re-entered the inner side, this suggested the presence of negative pressure in the thoracic space (Figure 1C). A mild change in body position was performed to clear the air at dead spaces as much as possible. If air leaks were found, a conventional intrapleural sealing test was carried out, and all air leaks were closed using sutures, staples or fibrin glue. A chest tube was placed if no air leakage was observed. On the other hand, the classical submergence method was to inflate the lung within a saline-filled pleural cavity held by a gauze ball [3]. The surgery was performed by a surgical team, including one surgical consultant, and procedures were selected based on the intraoperative situation.

\section{Postoperative management and follow-up}

All patients were extubated in the operating room. The chest tube was connected to an aspiration system, and negative suction of 5-or $10 \mathrm{cmH}_{2} \mathrm{O}$ was applied. Intercostal drains were removed when the underlying lung was expanded with no residual air leak. Postoperative pain was primarily controlled by means of a thoracic epidural block, oral analgesics were administered if necessary. Patients were discharged from the hospital when they were fully mobile. A follow-up was conducted for all patients. The median follow-up and relapse free periods were 134 and 207 days, respectively.

\section{Statistical analyses}

Categorical variables were evaluated using the chisquare test and the t-test was utilized to analyze continuous variables between the two groups. Differences were considered to be statistically significant for p-values < 0.05 . The data were analyzed using the Stat View software package (Abacus Concepts, Inc., Berkeley, CA).

\section{Results}

In all, 214 patients were studied in this retrospective review. All of the patients were Japanese, including 182 males and 32 females in this series, with a mean age of 38.8 years (range 14-94 years). We compared the clinicopathological characteristics between the patients evaluated using the new $(\mathrm{n}=35)$ and classical methods $(\mathrm{n}=$ 179). There were 35 (16.4\%) total postoperative recurrences. There were no significant differences in the age, gender, smoking, lesion site, location, comorbidities, ipsilateral SP (ISP), contralateral SP (CSP), or surgery for ISP between the new and standard methods (Table 1). Furthermore, there were no significant differences in the approach, covering, or surgeon (Table 2). However, the length of the operation and drainage period were significantly shorter for patients evaluated using the new method than the conventional method. There were no significant differences in the perioperative outcomes, including pleurodesis, or postoperative complications 

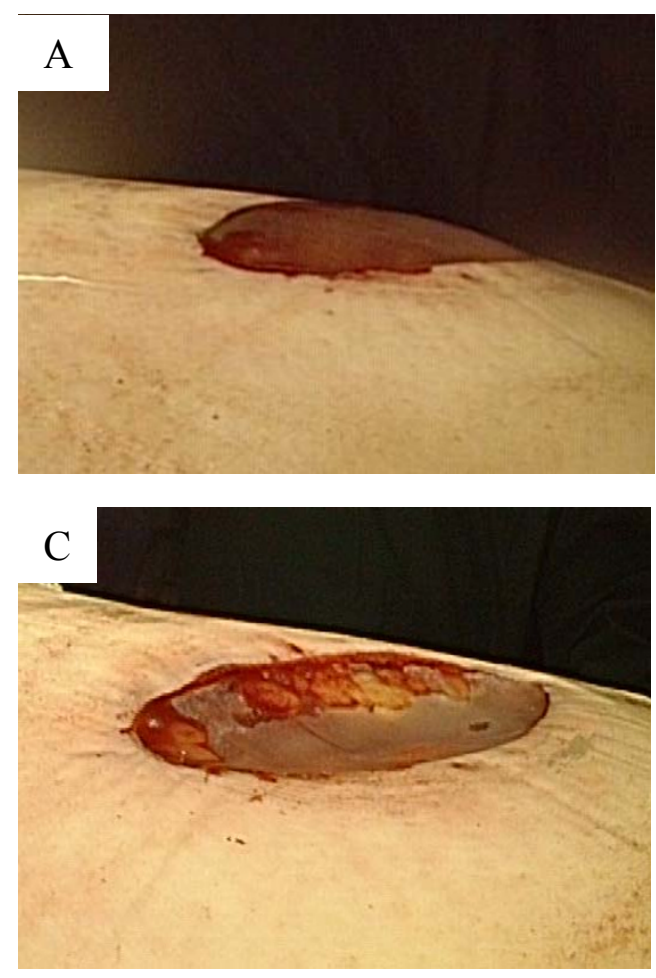

Figure 1 A: An intraoperative photo shows a schematic diagram of the new technique. If the covering film becomes convex this suggests that there is positive pressure in the thoracic space. B: A diagram showing the intraoperative view of (A). C: At the end of the procedure, if the transparent film has re-entered the inner side, this suggests the presence of negative pressure in the thoracic space (C). D: A diagram showing the intraoperative view of (C).

and recurrence (Table 3). Further, no postoperative complications were observed in patients evaluated using the new method.

\section{Discussion}

One of the most common complications after any procedure that involves the lung is PAL. Air leaks have also been shown to be more prevalent among patients with poor pulmonary function and among the elderly, who are making up an increasing number of such cases [2]. The only independent predictive factor for the recurrence of SP is the failure to identify and resect blebs during surgery [4]. The identification of blebs was formerly performed by a submersion method achieved by infiltrating the treated lung within the saline-filled pleural cavity [2]. This requires that the lung parenchyma be held to identify the leak point. Our postoperative recurrence rate after surgery was relatively high. These phenomena might be explained by the tendency to find more severe cases at university hospitals than in general clinics. We often experience postoperative air leaks in patients who did not have any air leaks during an operation. This is due, in part to the possibility of insufficient confirmation of the air leak points while undergoing surgery. It is desirable to test air leaks in the
B

D

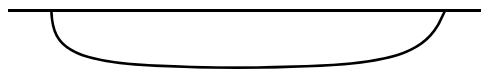

fully inflated lung because it represents a more natural way of measuring leaks. However, the working space of VATS is very narrow, which requires the lung parenchyma to be held in an unnatural state. In this situation, it is difficult to fully inflate the lung, making it more difficult to detect leaks. Thus, the surgeon may have to apply pressure to a partially front-and-center resected lung. However, this leads to both an incomplete evaluation, and a poorer evaluation of areas outside of the main lesion. These phenomena suggest that this test is inadequate. Therefore, we hypothesized that the evaluation of postoperative air leaks might be more effective when the residual lung is examined under a normal physiological state. Therefore, the submersion test can no longer be expected to provide good results for subjects who have undergone radical lung expansion.

We herein reported the development of a new method to test air leaks by using a transparent film and thoracic tube in a closed system. We believe that there are ten potential advantages associated with this new technique, without any apparent disadvantages. (1) The length of the operation and drainage periods were significantly shorter in patients evaluated using the new compared to the conventional method. This result can provide major benefits for the patients because it allows for minimally- 
Table 1 The relationships between operation method and clinicopathological characteristics

\begin{tabular}{|c|c|c|c|c|c|}
\hline Characteristic & Total & New & $\%$ & Classical & $p$-value \\
\hline All cases & 214 & 35 & 16.4 & 179 & \\
\hline \multicolumn{6}{|l|}{ Age (years) } \\
\hline$<28$ & 102 & 19 & 18.6 & 83 & \\
\hline$\geq 28$ & 112 & 18 & 16.1 & 94 & 0.391 \\
\hline \multicolumn{6}{|l|}{ Gender } \\
\hline Male & 182 & 31 & 17.0 & 151 & \\
\hline Female & 32 & 4 & 12.5 & 28 & 0.523 \\
\hline \multicolumn{6}{|l|}{ Smoking } \\
\hline Exist & 75 & 11 & 14.7 & 64 & \\
\hline None & 139 & 24 & 17.3 & 115 & 0.624 \\
\hline \multicolumn{6}{|l|}{ Lesion site } \\
\hline Right & 103 & 20 & 19.4 & 83 & \\
\hline Left & 111 & 15 & 13.5 & 96 & 0.243 \\
\hline \multicolumn{6}{|l|}{ Lesion location } \\
\hline Top & 177 & 28 & 15.8 & 149 & \\
\hline Other than top & 37 & 7 & 18.9 & 30 & 0.643 \\
\hline \multicolumn{6}{|l|}{ Comorbidities } \\
\hline Yes & 44 & 6 & 13.6 & 38 & \\
\hline No & 170 & 29 & 17.1 & 141 & 0.584 \\
\hline \multicolumn{6}{|l|}{$I S P^{a}$} \\
\hline Yes & 50 & 10 & 20.0 & 40 & \\
\hline No & 164 & 25 & 15.2 & 139 & 0.426 \\
\hline \multicolumn{6}{|l|}{$\mathrm{CSP}^{\mathrm{b}}$} \\
\hline Yes & 37 & 8 & 21.6 & 29 & \\
\hline No & 177 & 27 & 15.3 & 150 & 0.341 \\
\hline \multicolumn{6}{|l|}{ Operation for ISP } \\
\hline Yes & 22 & 5 & 22.7 & 17 & \\
\hline No & 192 & 30 & 15.6 & 162 & 0.394 \\
\hline
\end{tabular}

${ }^{a}$ ISP: ipsilateral spontenious pneumothorax, ${ }^{\mathrm{b}} \mathrm{CSP}$ : contralateral spontenious pneumothorax

invasive surgery and decreases the cost of medical care. (2) This method is performed in a natural and physiological state (3) It is easy to perform. (4) It takes just a few minutes to perform. (5) The new method does not

Table 2 The relationships between operation method and intraoperative factors

\begin{tabular}{lccccc}
\hline Characteristic & Total & New & $\%$ & Classical & $\begin{array}{c}p \text { - } \\
\text { value }\end{array}$ \\
\hline $\begin{array}{l}\text { Approach } \\
\quad \text { VATS }\end{array}$ & 189 & 32 & 16.9 & 157 & \\
$\quad \begin{array}{l}\text { thoracotomy } \\
\text { Covering }\end{array}$ & 25 & 3 & 12.0 & 22 & 0.531 \\
$\quad$ Use & 173 & 28 & 16.2 & 145 & \\
$\quad$ Non-use & 41 & 7 & 17.1 & 34 & 0.890 \\
$\begin{array}{l}\text { Surgeon } \\
\quad \text { Consultant }\end{array}$ & 103 & 13 & 12.6 & 90 & \\
$\quad$ Trainee & 111 & 22 & 19.8 & 89 & 0.155 \\
$\begin{array}{l}\text { Operation time } \\
\text { (min) }\end{array}$ & & $99.4(40-315)$ & & $130.2(35-285)$ & 0.046 \\
\hline
\end{tabular}

Table 3 Periopetative outcomes

\begin{tabular}{lccccc}
\hline Characteristic & Total & New* & $\%$ & Classical & $\begin{array}{c}p- \\
\text { value }\end{array}$ \\
\hline $\begin{array}{l}\text { Pleurodesis } \\
\quad \text { Yes }\end{array}$ & 15 & 0 & 0.0 & 15 & \\
$\quad$ No & 199 & 35 & 17.6 & 164 & 0.078 \\
$\begin{array}{l}\text { Postoperative } \\
\text { complication }\end{array}$ & & & & & \\
$\quad$ Yes & 15 & 0 & 0.0 & 15 & \\
$\quad$ No & 199 & 35 & 17.6 & 164 & 0.08 \\
$\begin{array}{l}\text { Postoperative } \\
\text { recurrence }\end{array}$ & & & & & \\
$\quad$ Yes & 35 & 7 & 20.0 & 28 & \\
$\quad$ No & 179 & 28 & 15.6 & 151 & 0.524 \\
$\begin{array}{l}\text { Drainage periods } \\
\text { (day) }\end{array}$ & & $1.857(1-3)$ & & $2.268(1-9)$ & 0.031 \\
\hline
\end{tabular}

require saline, which might cause pneumonia due to suction into the ventilated lung (6) Taking up the transparent film after sealing can clean up excrescent clots of blood, coagulation, and necrotic material, decreasing the risk of surgical site infection (7). This technique might be useful not only for SP, but also for limited resections such as wedge resection and segmentectomy for lung tumors (8). This method can be used for lungs treated en bloc rather than just from one region to the next. (9) This technique is inexpensive, and the transparent film costs just $¥ 308$ (\$3.76US). (10) Our technique is also accurate, is associated with very little risk, and will likely progress due to the expected advances in surgery in the future [5], especially since thoracoscopy has recently become popular, and most thoracic surgeons are already familiar with the procedure [6].

Nevertheless, our findings include several limitations for interpretation; primarily the retrospective nature of the study and the fact that it was carried out at a single institution. To overcome these limitations, prospective studies in a larger cohort of patients and at different institutions will be necessary to clarify the efficacy of this method. In conclusion, we herein presented a novel method for evaluating air leaks without submergence, decreasing the risk of unexpected air leaks after surgery.

\section{Abbreviations}

SP: spontaneous pneumothorax; PAL: prolonged air leak; VATS: videoassisted thoracoscopic surgery; ISP: ipsilateral spontaneous pneumothorax; CSP: contralateral spontaneous pneumothorax; $\mathrm{CT}$ : computed tomography; LAM: lymphangioleiomyomatosis; PGA: polyglycolic acid.

\section{Authors' contributions}

This report reflects the opinion of the authors and does not represent the official position of any institution or sponsor. The contributions of each of the authors were as follows:

$\mathrm{HU}$ were responsible for reviewing previous research, journal hand searching, and drafting report. FT was responsible for project coordination. All authors have read and approved the final manuscript. 


\section{Competing interests}

The authors declare that they have no competing interests.

Received: 12 June 2011 Accepted: 24 December 2011

Published: 24 December 2011

\section{References}

1. Muramatsu T, Nishii T, Takeshita S, Ishimoto S, Morooka H, Shiono M: Preventing recurrence of spontaneous pneumothorax after thoracoscopic surgery: a review of recent results. Surg Today 2010, 40:696-9.

2. Abolhoda A, Liu D, Brooks A, Burt M: Prolonged air leak following radical upper lobectomy: an analysis of incidence and possible risk factors. Chest 1998, 113:1507-10.

3. Toloza EM, Harpole DH Jr: Intraoperative techniques to prevent air leaks. Chest Surg Clin N Am 2002, 12:489-505.

4. Naunheim KS, Mack MJ, Hazelrigg SR, Ferguson MK, Ferson PF, Boley TM, Landreneau RJ: Safety and efficacy of video-assisted thoracic surgical techniques for the treatment of spontaneous pneumothorax. J Thorac Cardiovasc Surg 1995, 109:1198-203.

5. Uramoto $H$, Takenoyama M, Hanagiri T: Simple prophylactic fixation for lung torsion. Ann Thorac Surg 2010, 90:2028-30.

6. Oka S, Uramoto H, Hanagiri T: Successful extirpation of thoracic pleural lipoma by single port thoracoscopic surgery. Asian I Surg .

doi:10.1186/1749-8090-6-165

Cite this article as: Uramoto and Tanaka: Natural air leak test without submergence for spontaneous pneumothorax. Journal of Cardiothoracic Surgery 2011 6:165.

\section{Submit your next manuscript to BioMed Central} and take full advantage of:

- Convenient online submission

- Thorough peer review

- No space constraints or color figure charges

- Immediate publication on acceptance

- Inclusion in PubMed, CAS, Scopus and Google Scholar

- Research which is freely available for redistribution

Submit your manuscript at www.biomedcentral.com/submit 